\title{
Mesoscale inversion: first results from the CERES campaign with synthetic data
}

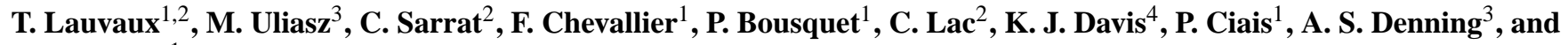 \\ P. J. Rayner ${ }^{1}$ \\ ${ }^{1}$ Laboratoire des Sciences du Climat et de l'Environnement/IPSL,CEA-CNRS-UVSQ, Gif-sur-Yvette, France \\ ${ }^{2}$ Centre Nationale des recherches Météorologiques, Toulouse, France \\ ${ }^{3}$ Department of Atmospheric Sciences, Colorado State University, Fort Collins, Colorado, USA \\ ${ }^{4}$ Department of Meteorology, The Pennsylvania State University, University Park, Pennsylvania, USA
}

Received: 25 April 2007 - Published in Atmos. Chem. Phys. Discuss.: 19 July 2007

Revised: 13 February 2008 - Accepted: 7 June 2008 - Published: 2 July 2008

\begin{abstract}
We investigate the ability of a mesoscale model to reconstruct $\mathrm{CO}_{2}$ fluxes at regional scale. Formally, we estimate the reduction of error for a $\mathrm{CO}_{2}$ flux inversion at $8 \mathrm{~km}$ resolution in the South West of France, during four days of the CarboEurope Regional Experiment Strategy (CERES) in spring 2005. Measurements from two towers and two airplanes are available for this campaign. The lagrangian particle dispersion model LPDM was coupled to the nonhydrostatic model Meso-NH and integrated in a matrix inversion framework. Impacts of aircraft and tower measurements are quantified separately and together. We find that the configuration with both towers and aircraft is able to significantly reduce uncertainties on the 4-day averaged $\mathrm{CO}_{2}$ fluxes over about half of the $300 \times 300 \mathrm{~km}^{2}$ domain. Most of this reduction comes from the tower measurements, even though the impact of aircraft measurements remains noticeable. Imperfect knowledge of boundary conditions does not significantly impact the error reduction for surface fluxes. We test alternative strategies to improve the impact of aircraft measurements and find that most information comes from measurements inside the boundary layer. We find that there would be a large improvement in error reduction if we could improve our ability to model nocturnal concentrations at tower sites.
\end{abstract}

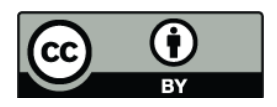

Correspondence to: T. Lauvaux (thomas.lauvaux@1sce.ipsl.fr)

\section{Introduction}

Construction of a coherent picture of the global carbon cycle, compatible with all available observations remains an important and elusive scientific challenge. The two complementary approaches are termed bottom-up or top-down. In bottomup approaches pointwise estimates of $\mathrm{CO}_{2}$ exchange at the surface (Baldocchi et al., 2001) are integrated in space and time or are used to validate and calibrate land surface models (Krinner et al., 2005) together with satellite retrievals of surface properties. In top-down approaches, these integrated fluxes are inferred from their signatures on atmospheric concentration after being transported in the atmosphere (Enting, 2002). A coherent description requires that both methods provide statistically consistent flux estimates. Furthermore, the uncertainties on the two estimates must be small enough that each estimate carries meaningful information. Uncertainties on bottom-up estimates increase with spatial scale (as more extrapolation is required) while uncertainties on topdown estimates increase with decreasing scale due to the illconditioning of the inverse problem and the smoothing of atmospheric transport (Enting, 2002). The problem is complicated by the difficulties of simulating atmospheric transport at smaller scales on the continents (Geels et al., 2007; PérezLanda et al., 2007). There have been very few cases with dense enough observations to test consistency. The CERES campaign described below (Dolman et al., 2006) is an attempt to do this over a limited domain. This paper describes the components of a top-down inversion system to estimate fluxes over the domain of CERES and to evaluate the potential of various atmospheric measurements to constrain fluxes. Actual inversion estimates will be described in a future paper once all necessary data is validated.

Published by Copernicus Publications on behalf of the European Geosciences Union. 


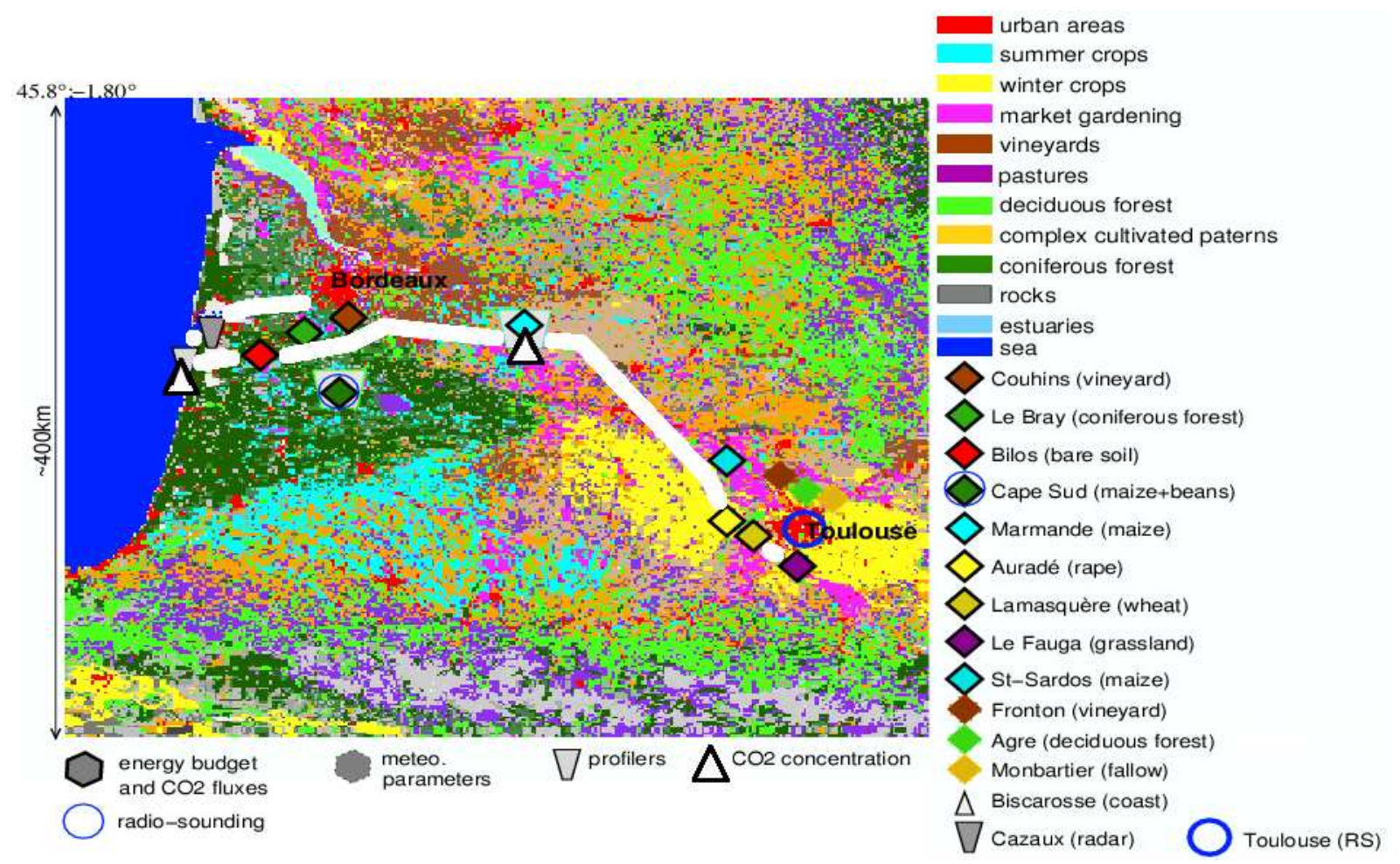

Fig. 1. Map of the vegetation types and the instrumentation over the CERES domain for the 2005 campaign.

The potential of measurements is evaluated by their impact on the posterior uncertainty of fluxes (e.g. Gloor et al., 2000; Rayner and O'Brien, 2001; Law et al., 2003). In principle this requires only knowledge of the prior uncertainty covariances for data and concentrations plus knowledge of atmospheric transport, i.e. no dependence on data or fluxes themselves. However there is a requirement for consistency between the quality of the final simulation (difference between simulated and observed concentrations) and the data uncertainty (Michalak et al., 2005). Realistic evaluation of possible data must therefore consider the ability of the modelling system to simulate it. The paper therefore includes a simple comparison of prior simulation and observed concentrations.

The outline of the paper is as follows: First we briefly review the CERES campaign. Then we introduce the various elements of the inversion system. We commence the results with a brief comparison of the a priori simulation and observations then discuss the constraint afforded by the various observations. Finally we investigate various alternative strategies for airborne and tower sampling.

\section{Description of CERES}

During CERES (Dolman et al., 2006), $\mathrm{CO}_{2}$ concentration measurements on instrumented towers and aircraft were collected during six weeks in May-June 2005. The CERES domain includes the pine forest of Les Landes (West) and a large agricultural area with a mixture of winter and summer crops, in the south west of France (Fig. 1), from Bordeaux in the north west to Toulouse in the south east. Compared to other regional studies involving aircraft (e.g. Stephens et al., 2000; Gerbig et al., 2003; Filippi et al., 2003), the CERES domain covers a smaller region of about $300 \times 300 \mathrm{~km}$ with several flights each day. Other experiments on similarlysized domains were described by (Uliasz et al., 2005) which comprised a larger set of instrumented towers but without aircraft, and, Dolman et al. (2002) where aircraft were used but without towers.

The CERES experiment involved two aircraft measuring atmospheric $\mathrm{CO}_{2}$ during several Intensive Observation Periods (IOP), and two towers (Marmande and Biscarosse) measuring atmospheric $\mathrm{CO}_{2}$ continuously (Fig. 1). Both towers provide $\mathrm{CO}_{2}$ concentrations every $30 \mathrm{~min}$, which we average hourly. The Biscarosse tower is located $2 \mathrm{~km}$ from the Atlantic shore, in the pine forest of Les Landes, at $50 \mathrm{~m}$ height on a $70 \mathrm{~m}$ hill. Marmande is located further inland, at $20 \mathrm{~m}$ height, between the pine forest and the agricultural area to 
the East. In this paper, we study a 4-day period between the 23 at 6 p.m. to the 27 of May at 12 p.m. which includes the second IOP of the campaign (26 and 27 of May 2005). The two aircraft, a Piper-Aztec and an ECO-Dimona, flew ten times between the 23 and 27 of May during the morning and the early afternoon, with different transects in the region. We used all the flights in this study. Some flights consist of a vertical profile above the pine forest; some others correspond to a transect from Biscarosse to Marmande, and also longer ones from Bordeaux to Toulouse mostly in the planetary boundary layer. $\mathrm{CO}_{2}$ concentrations are measured at high frequency $(1 \mathrm{~Hz})$, then averaged to three-minute periods as detailed below.

\section{Models}

In order to perform a mesoscale inversion, the nonhydrostatic atmospheric mesoscale model MesoNH (Lafore et al., 1998) was coupled offline to the lagrangian dispersion model LPDM (Uliasz, 1994). MesoNH enables us to simulate atmospheric dynamics at high resolution within the domain together with high frequency $\mathrm{CO}_{2}$ observations of the CERES campaign. The Lagrangian model is computationally efficient enough to allow the multiple backward tracer calculations required for the inversion. While the resolution of mesoscale models improves the simulation (and hence utility) of observations it comes at the cost of a limited domain size and limited duration. We use a two-way nesting with resolutions of $8 \mathrm{~km}$ and $2 \mathrm{~km}$ with 65 levels to $13 \mathrm{~km}$ altitude. We simulated the 27 of May at $2 \mathrm{~km}$ resolution which is an intensive period of flights, and included it in the longer simulation of 23-27 May at $8 \mathrm{~km}$ resolution. The 2-way nesting configuration keeps the consistency of the dynamics between the different grids, which allows us to use the particle distributions from different runs together. These two simulations use the analysed data from the ECMWF as initial and boundary conditions. Dynamical fields were saved each $20 \mathrm{~min}$, or five min during the flights, for the off-line coupling with a lagrangian model. The dynamical fields at $2 \mathrm{~km}$ resolution allow a more precise description of the vertical transport during the flights. An intercomparison study between different RAMS (Regional Atmospheric Modeling System) model versions, WRF (Weather Research and Forecasting model), and MesoNH (all coupled with biospheric models and prescribed anthropogenic emissions) showed their ability to reproduce observed $\mathrm{CO}_{2}$ concentrations measured by aircraft during the CERES campaign (Sarrat et al., 2007).

The tracer backward transport was simulated here by the Lagrangian Particle Dispersion Model (LPDM) described by Uliasz (1994). Particles are released from the receptors in a "backward in time" mode with the wind fields generated by the eulerian model MesoNH. In a "backward in time" transport mode, particles are released in LPDM from the measure- ment locations and travel to the surface and the boundaries. Compared to a forward mode, all the particles here are used to estimate fluxes, which reduces the computational cost of the simulation. The lagrangian model LPDM was enhanced to simulate aircraft observations based on the precise trajectory of the airplane estimated by GPS (Global Positioning System). At each second, 10 particles are released at the position of the aircraft. A longer integration time would yield more particles and hence more reliable Lagrangian statistics but would misrepresent the aircraft trajectory. We use higher resolution for the aircraft measurement period because the eventual particle distributions are more sensitive to the explicitly resolved vertical velocity.

The dynamical fields in LPDM are forced by mean horizontal winds $(\mathrm{u}, \mathrm{v})$, potential temperature, and turbulent kinetic energy (TKE) from MESO-NH. At this resolution (less than $10 \mathrm{~km}$ ), turbulent motion corresponds to the closure of the energy budget at each time step. This scalar is used to quantify turbulent motion of particles as a pseudo random velocity. Based on the TKE, wind, and potential temperature, the lagrangian model diagnoses turbulent vertical velocity and dissipation of turbulent energy. The off-line coupling between an Eulerian and a Lagrangian model solves most of the problems of non-linearity in the advection term at the mesoscale. Most of the non-linear processes resolved by the atmospheric model are attributed to a scalar representing the velocity of the particles.

At each timestep (from one to $20 \mathrm{~s}$ ), particles move with a velocity interpolated from the dynamical fields of the MESO$\mathrm{NH}$ simulation (5 or $20 \mathrm{~min}$ ). The timestep depends on the TKE, following the discretization described in Thomson (1987). Each time a particle touches the surface, its position and release time are saved. Particles here should not be considered as individual molecules (lost when touching the surface) but as an air parcel influenced by $\mathrm{CO}_{2}$ fluxes as it moves along the ground.

The formalism for inferring source-receptor relationships from particle distributions is described by Seibert et al. (2004). At each time step, the fraction of particles (released from one receptor at one time) within some volume, gives the influence of that volume on the receptor. If the volume includes the surface this will yield the influence of surface sources. If the volume includes the boundary (sides or top) it yields the influence of that part of the boundary. The particle distribution at the beginning of the study period defines the influence of the initial condition. The influence function is thus decomposed into three different terms, corresponding to the initial concentration, the surface source contribution, and the boundary fluxes (Peylin et al., 2005).

Mesoscale inversions face the problem of modelling a limited domain with potentially high contributions from the boundary fluxes. Regional inversions at the continental scale (e.g. Gerbig et al., 2003) use large domains and long study periods to decrease the impact of the lateral boundary and initial concentrations. In our study, the time period and domain 
size are limited by computational cost which forces us to deal with both explicitly. Concentrations at domain boundaries are defined by a grid of $1^{\circ}$ by $1^{\circ}$ resolution (as typically used by atmospheric general circulation models) on the horizontal and 2 levels on the vertical corresponding to the boundary layer and the free troposphere. The two levels for the boundary fluxes appear as additional unknowns in the inverse system. To separate these layers, we use an averaged height of the boundary layer, given by the daily mean boundary layer top. This coarse description of the boundaries has the advantage of introducing fewer unknowns in the inversion, and still makes it possible to study the impact of boundaries on the different receptors. The spatial extent of an aircraft observation is defined by the integration time for the related observation. A time interval of 3 min produced the best compromise between the need for sufficient particles to gather good statistics and the ability to resolve the observed distribution. Considering the velocity of the aircraft (about $150 \mathrm{~km} / \mathrm{h}$ ), a 3-min time window corresponds to a receptor of less than $8 \mathrm{~km}$ long, which is the resolution of the dynamical fields in Meso-NH.

\section{Inversion}

The lagrangian model backward simulations provide the matrix of influence functions (frequently called the Jacobian $\mathbf{J}$ ): the sensitivity of each observation to each unknown. The size of the $\mathbf{J}$ matrix corresponds to the dimension of the vector of surface fluxes plus the unknown boundary concentrations. The surface fluxes comprise $90 \times 90$ points multiplied by the time resolution of surface fluxes $\delta T$ (either 1 for a mean flux or 2 for a split of day and night as explained below).

The boundary concentrations are divided into two levels and 5 horizontal grid cells for each side of the domain. The observations consist of 102 hourly concentration measurements from each tower plus an observation each 3 min from each flight, i.e. 852 observations for the ten flights. The number of elements in the $\mathrm{J}$ matrix is finally $8140 \times \delta T \times 102 \times 2$ $+8140 \times \delta T \times 852$.

The dimension of $\mathbf{J}$ makes it possible to solve the inverse problem using the classical matrix solution for one averaged flux per grid cell over the four days or for separate averaged fluxes for day and night. (e.g. Tarantola, 1987; Enting, 2002). Briefly we minimize a cost function:

$$
\begin{aligned}
\chi^{2}= & \frac{1}{2}\left[\left(\boldsymbol{s}-\boldsymbol{s}_{0}\right)^{T} \mathbf{C}\left(\boldsymbol{s}_{0}\right)^{-1}\left(\boldsymbol{s}-\boldsymbol{s}_{0}\right)\right. \\
& \left.+(\mathbf{J} \boldsymbol{s}-\boldsymbol{d})^{T} \mathbf{C}(\boldsymbol{d})^{-1}(\mathbf{J} \boldsymbol{s}-\boldsymbol{d})\right]
\end{aligned}
$$

Where $s$ represents the unknown sources we seek, $s_{0}$ the a priori source estimate, $\boldsymbol{d}$ the observed data and $\mathbf{C}(\boldsymbol{x})$ the uncertainty covariance of a vector quantity. $\boldsymbol{s}$ and $\mathbf{J}$ include concentrations at the boundary as described above. Minimizing the equation with respect to $s$ yields

$\boldsymbol{s}=\boldsymbol{s}_{0}+\mathbf{C}\left(\boldsymbol{S}_{0}\right) \mathbf{J}^{T}\left(\mathbf{J C}\left(\boldsymbol{s}_{0}\right) \mathbf{J}^{T}+\mathbf{C}(\boldsymbol{d})\right)^{-1}\left(\boldsymbol{d}-\mathbf{J} \boldsymbol{s}_{0}\right)$

More important for this work is the posterior error covariance for sources given by the expression:

$\mathbf{C}(\boldsymbol{s})^{-1}=\mathbf{C}\left(\boldsymbol{s}_{0}\right)^{-1}+\mathbf{J}^{T} \mathbf{C}(\boldsymbol{d})^{-1} \mathbf{J}$

We do not solve $s$ in this paper, but focus on the uncertainties of $s(\mathbf{C}(s))$ that do not depend on the observations $\boldsymbol{d}$ but only on their errors $\mathbf{C}(\boldsymbol{d})$ and a prior error covariance $\mathbf{C}\left(\boldsymbol{s}_{0}\right)$. We notice in Eq. (3) that the posterior covariance $\mathbf{C}(s)$ depends on the prior covariance $\mathbf{C}\left(\boldsymbol{s}_{0}\right)$. This dependence will be discussed for our inversion by doubling the prior uncertainty for the lateral boundaries, to estimate the impact on the error reduction for the surface and the boundaries. The value of the prior flux error was set to $2 \mathrm{gm}^{-2} \mathrm{day}^{-1}$ for the surface and $4 \mathrm{ppm}$ for the boundaries.

Concerning the estimation of the observation uncertainty, we assessed it by the comparison of the model results with aircraft data during the day, and tower data during day and night. The largest difference is about $3 \mathrm{ppm}$ on different flights of the 27 of May. Taking into account the uncertainty of the LPDM model, and the lack of temporal correlations, we set this diurnal observation error at $4 \mathrm{ppm}$. The diurnal variability of the model error for tower data is shown in the section 6 over the four days.

Finally, we define the error reduction as :

$\boldsymbol{r}=\frac{\sigma_{\text {post }}}{\sigma_{\text {prior }}}$

where $\boldsymbol{\sigma}(\boldsymbol{x})$ is the square root of the diagonal of $\mathbf{C}(\boldsymbol{x}) . \sigma_{\text {post }}$ represents the posterior error, and $\sigma_{\text {prior }}$ the prior error. Retrieving a single mean flux over four days is equivalent to retrieving fluxes at every time step but assuming perfect temporal correlation for every point. From the study of Chevallier et al. (2006) based on daily $\mathrm{CO}_{2}$ fluxes simulated by a biosphere model and $\mathrm{CO}_{2}$ flux observations, the time correlation of the differences between modelled and observed $\mathrm{CO}_{2}$ fluxes is still more than 0.5 after 5 days. Our assumption of a perfect error correlation over four days is therefore defensible. Concerning the spatial correlation of the prior error covariance, we assumed uncorrelated flux errors on the domain, as the weakest constraint for this inversion. Using a spatial error correlation would lead to assume spatial coherences in $\mathrm{CO}_{2}$ flux errors which were not clearly identified at this scale by Chevallier et al. (2006). We do not expect our prior fluxes to capture the amplitude of the diurnal cycle. We hence allow separate correction of diurnal and nocturnal mean fluxes. The separation is somewhat similar to that of Zupanski et al. (2007) but separated by time rather than by process. We also investigate the more optimistic option where the prior flux captures diurnal variability sufficiently that we need only correct the daily mean. 


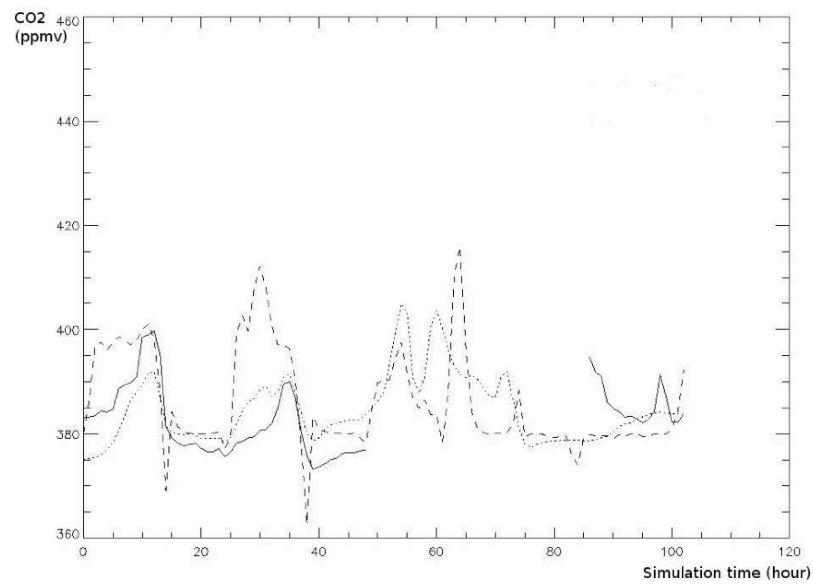

(a)

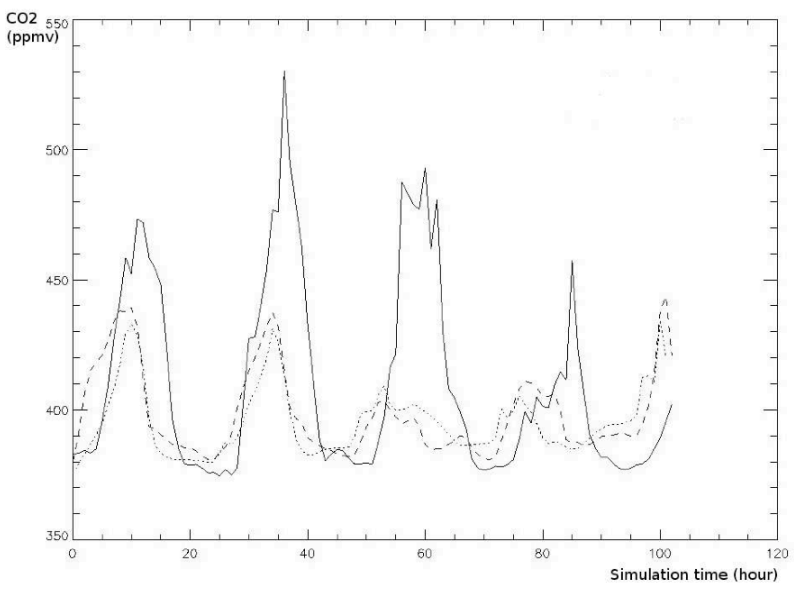

(b)

Fig. 2. $\mathrm{CO}_{2}$ concentrations observed (solid line), modelled with MesoNH and ISBA-A-gs (dashed line), and modelled with our linearised transport for the inversion (dotted line), at the tower of (a) Biscarosse and (b) Marmande from the 23 of May at 6 p.m. to the 27 at 12 p.m.

\section{Experiments}

From Eq. 3, the error reduction depends on the prior and observation error covariance matrices and the Jacobian. For the observation error, the model error is the main contribution in our inversion system, compared to measurement uncertainty, aggregation and representation errors. We estimated, for each tower, the difference between modelled and measured atmospheric $\mathrm{CO}_{2}$ concentrations during the four days using the prior estimates of flux. Additionally, we present the results from the direct simulation of MesoNH coupled with ISBA-A-gs to identify any differences between the inverse linearised transport model and the initial direct simulation used to generate the influence functions. This comparison will be used to introduce the temporal structure of the uncertainty and its related impact on the error reduction.

We conducted three experiments with the inverse system. For each of them we optimized $\mathrm{CO}_{2}$ fluxes for the four days of measurements and for each model pixel at $8 \mathrm{~km}$ resolution. In the first experiment, we tested the potential of the observations performed during the CERES campaign to reduce uncertainties on $\mathrm{CO}_{2}$ fluxes. This study produces maps of error reduction over the domain. The error reduction was mapped to a final resolution at $8 \mathrm{~km}$. The different receptors are simulated separately during the period. Biscarosse, Marmande, and ten different flights were combined to estimate the final potential of the method. The last case uses only the two towers, but we separated the flux into two terms, a diurnal and a nocturnal, including the temporal structure of the observation uncertainty from the previous result. We assess here the impact of the nocturnal and diurnal observations in the system considering the previous comparison.

The second experiment aimed at optimizing the flight paths of the next CERES campaign planned for April and September 2007. For this, we tested different altitudes of virtual flights in the boundary layer and tried to infer an optimal height from diagnostics of particle distributions and from the spatial extent of the influence function. Based on one flight from the 2005 CERES campaign, we created 12 virtual flights with constant altitudes from 100 to 2500 meters. The horizontal coordinates used for these virtual flights correspond to a long transect from Bordeaux to Toulouse. This optimization gives a first constraint on aircraft measurement strategy and on the dependency of spatial extent of the fluxes influencing the observations to flight altitudes .

In a third experiment, the impact of the altitude of $\mathrm{CO}_{2}$ measurement towers was investigated. The sampling altitude of near-ground stations continuously measuring $\mathrm{CO}_{2}$ largely determines the spatial extent of the area influencing the measurements. Tall towers observe $\mathrm{CO}_{2}$ concentrations in the mixed layer and are able to provide information coming from larger areas (Davis et al., 2003; Gloor et al., 2001). We modelled here a potential tall tower of $300 \mathrm{~m}$ height at the exact position of the actual Biscarosse tower (real altitude is $50 \mathrm{~m}$ ). The spatial variation of the surface flux contribution is then compared to the actual one over the 4-day period.

\section{Results}

During this 4-day period, $\mathrm{CO}_{2}$ concentrations were measured continuously at the two towers, except for a gap in the data series of Biscarosse starting the 25 of May at $6 \mathrm{p} . \mathrm{m}$. for about $40 \mathrm{~h}$. The comparison of the prior fluxes transported by our jacobian with the data shows the diurnal variability of the observation error, much larger during nighttime than daytime, especially at the Marmande tower (Fig. 2). The nocturnal 
accumulation of the atmospheric $\mathrm{CO}_{2}$ at this site reaches 530 ppmv during the second night, whereas the modelled concentrations in the direct simulation and for the linearised transport reach about 430 ppmv and 440 ppmv respectively. During the day, the difference between the observed $\mathrm{CO}_{2}$ concentrations and the linearised transport solution is about 5 ppmv for the two tower measurement sites, consistent with the previous quantification of the observation uncertainty. At the biscarosse tower measurement site, the diurnal variability of the $\mathrm{CO}_{2}$ concentrations is about 20 ppmv, with an error of about 10 ppmv compared to the two modelled $\mathrm{CO}_{2}$ concentrations. The linearised transport solution shows a large diurnal cycle up to $25 \mathrm{ppmv}$, slightly higher than observed at the tower. Although these errors seem large, (Michalak et al., 2005) noted that, for statistical coherence, the prior simulation error must be smaller than the observational error plus the prior flux error projected into concentration space. Here we use the structure of the error mainly for guidance; it is clear for example that nighttime data at Marmande would be hard to use.

The backward in time simulation begins on the 28 at midnight and lasts 4 days until the 23 of May at $6 \mathrm{pm}$. At the end of the afternoon of the 27, a northerly wind prevails at the Biscarosse tower, parallel to the sea shore. During the 26 and the 27 of May, a sea breeze starts around noon, affecting the Biscarosse tower (Fig. 3b). The footprint of the Biscarosse measurement tower is then localised to the West of the tower, over the Atlantic Ocean. During the 27, the Marmande tower is affected by a strong south eastern wind, amplified by a valley effect. This wind, called the "Autan wind", is generated by the usual synoptic conditions at this period of the year, with a low pressure system over the Pyrenees mountains. The cyclonic system induced by the low pressure forces the air mass from the mediterranean sea to enter the valley between the Pyrenees mountains and the Montagne Noire (Fig. 3a). During the previous night, between the 26 and the 27 of May, the two towers show similar footprints to the south east of the measurement towers, corresponding to the Autan wind situation. At the Marmande tower, even though the main wind direction remains SouthEasterly, the plume of particles during the 26 of May shows a wave distribution corresponding to changes in the wind direction. During the 24 and the 25 of May, similar meteorological situations occur alternatively over the domain.

Figure 3 shows the dominant boundary influence from the West of the domain for the beginning of the 4-day period. The dominant location changes during the other days, but remains localised, which justifies the fine description of boundary conditions. Considering the particles released from Biscarosse, we estimated the time distribution of the particles reaching the boundaries during the 27 of May (Fig. 5). Within $15 \mathrm{~h}$ (backward in time) of their release, $99 \%$ of them left the domain. This result defines the maximum backward integration time for LPDM. Beyond this (earlier in time) there are no more particles in the domain hence no fluxes that affect this observation. It also defines the time period of observations affected by the initial condition. The synoptic winds were weak during May 27 (about $3 \mathrm{~m} / \mathrm{s}$ ), which makes this estimation an upper limit for the other days.

For the first experiment, we ran an inversion using only the two towers, measuring throughout the 4-day period (Fig. 6b). In the vicinity of the towers ( tens of $\mathrm{km}$ ), error reduction can reach $90 \%$ but decreases rapidly to $50 \%$. In the directions of the main daily winds, the reduction is about $30 \% 300 \mathrm{~km}$ from the towers, in a narrow band. On the boundaries, the reduction of error is less than $1 \%$ and almost uniform on different sides of the domain. When using only the flight from Biscarosse to Marmande (Fig. 6a), the largest error reductions (about $90 \%$ ) occur for one or two boundary pixels $(100 \mathrm{~km}$ per pixel) of the upper western boundary. South of the trajectory, error reduction is about $5 \%$ in a small region of few tens of $\mathrm{km}$. Another region at the East of the Pyrenees, also visible in the tower case, shows a reduction of about $1 \%$. The last inversion uses all the different available measurements during the second CERES IOP (Fig. 6c). It shows an extended error reduction around the towers from 60 to $90 \%$, but also some regions of larger error reduction in the East and South of the Pyrenees of 10 to $60 \%$. As in the aircraft case, a few grid cells of the upper boundary show a reduction of about $90 \%$, the rest being less than $10 \%$. The error reduction at the surface is extended by the different flights, and increased by 15 to $20 \%$. Even though one flight shows limited impact (Fig. 6b), the addition of the ten different flights is noticeable in the final error reduction.

The last setup demonstrates the capacity of the inverse system under more limiting assumptions. First, we solved for two different fluxes corresponding to the daily and the nocturnal averaged fluxes. Second, we introduced a large diurnal variability in the observation uncertainty $\mathbf{C}(\boldsymbol{d})$, of $4 \mathrm{ppmv}$ during the day, and 100 ppmv during the night, which corresponds roughly to neglecting the nighttime data. This extreme assumption also illustrates the impact of the nighttime data in estimating both daytime and nighttime $\mathrm{CO}_{2}$ fluxes. We used the results from the data comparison to estimate the observation error, showing large values during nighttime at Marmande tower, generalized here to both towers. The four different error reduction maps presented in the Fig. 7 show the error reduction when retrieving the diurnal or nocturnal fluxes, considering a constant observation uncertainty or a large diurnal variability in the model error. The spatial extent of significant error reduction is reduced by the increased number of unknowns (Fig. 7a and b), and also by the larger observation uncertainty (Fig. $7 \mathrm{c}$ and d). Concerning the cases using a constant observation error (Fig. 7a and b), the error reduction for the nocturnal flux shows a larger extension but the high values $(>30 \%)$ are reduced to a few pixels around the towers, compared to the daytime flux error reduction. If we increase the nighttime observation error (Fig. 7c and d), the error reduction decreases for both fluxes, which implies that the nighttime observations constrain daytime and 


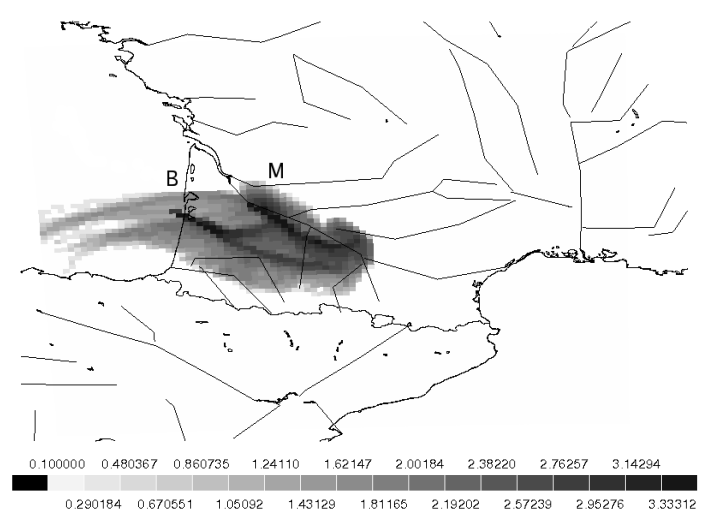

(a)

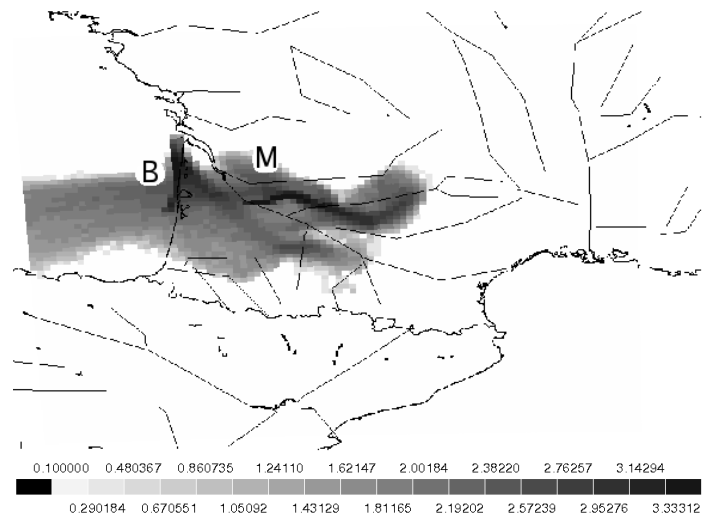

(b)

Fig. 3. Distribution of the particles (logarithmic scale) released from Biscarosse (B) and Marmande (M) towers (a) the 27 of May between 6:30 a.m. and 7:30 a.m. (b) the 26 of May between 8:30 p.m. 'and 9:30 p.m.

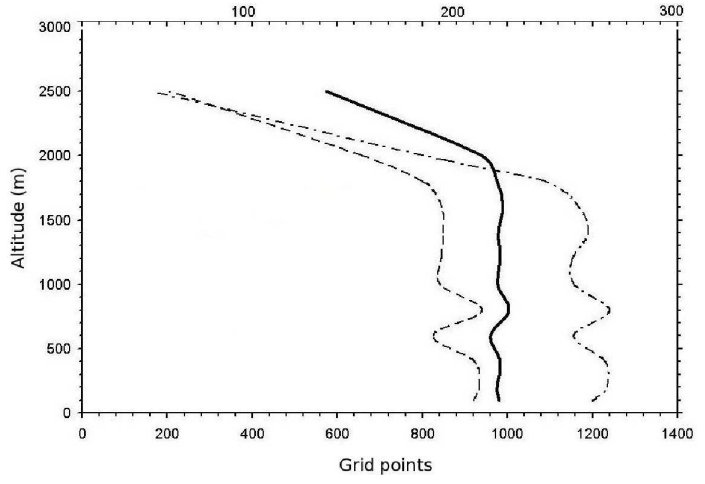

Fig. 4. Number of grid cells with an error reduction of $1 \%$ (solid line), with an error reduction equals or more than $30 \%$ (dashed line, top $\mathrm{x}$-axis) and the averaged value of the error reduction within the domain (dash-dotted line) depending on the altitude of the virtual flights.

nighttime fluxes in the same way. The nocturnal flux is mostly constrained by the nighttime observations as shown by the narrow high error reduction area around the tower, but the diurnal flux is also constrained mostly by the nighttime observations. During the morning, the low boundary layer height concentrates the particles near the surface, whereas the high boundary layer during the afternoon distributes the particles throughout the column. As both periods are considered diurnal observations, most of the surface influence happens during the morning. The surface influence is propagated (backward in time by transport) so that morning observations are strongly linked to night time fluxes.

The second experiment arises from the first one, where it appears that aircraft measurements are a weaker constraint than those from towers. In order to optimize this contribution, a series of 12 virtual flights was simulated at different

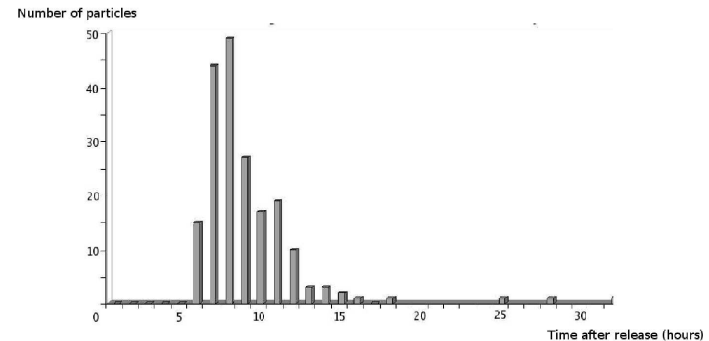

Fig. 5. Time distribution of the particles leaving the domain, released in a 400-s interval (equivalent to 200 particles) at Biscarosse tower.

altitudes, from $100 \mathrm{~m}$ to $2500 \mathrm{~m}$. Three different diagnostics were used to estimate the impact of the height of the trajectory on the surface contribution (Fig. 4): the number of grid cells with a number of particles corresponding to an error reduction greater than $1 \%$, the highest reductions of error of each flight, and the averaged error reduction for all the surface grid cells for each flight. The three different measures are constant in the boundary layer, and decrease quickly above it, with almost the same shape. Between $500 \mathrm{~m}$ to $1000 \mathrm{~m}$, the three measures of error reduction vary due to a change in the horizontal mean wind. A local horizontal wind shear affects the particle distribution when the simulated aircraft flies in one of the main horizontal winds. The vertical mixing in the boundary layer is strongly dominant compared to the horizontal mixing, implying that any flight measurement at one location within the boundary layer will be influenced by a similar surface area.

The last experiment uses only the Biscarosse tower. Thanks to the high resolution of the transport model, we estimated the area of influence in the case of a tall tower $(300 \mathrm{~m})$ at Biscarosse. Figure 8a shows the particle "touchdowns" 


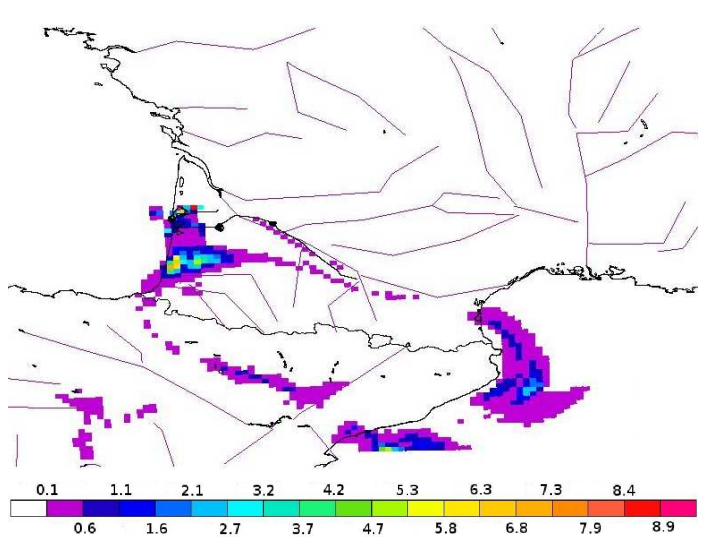

(a)

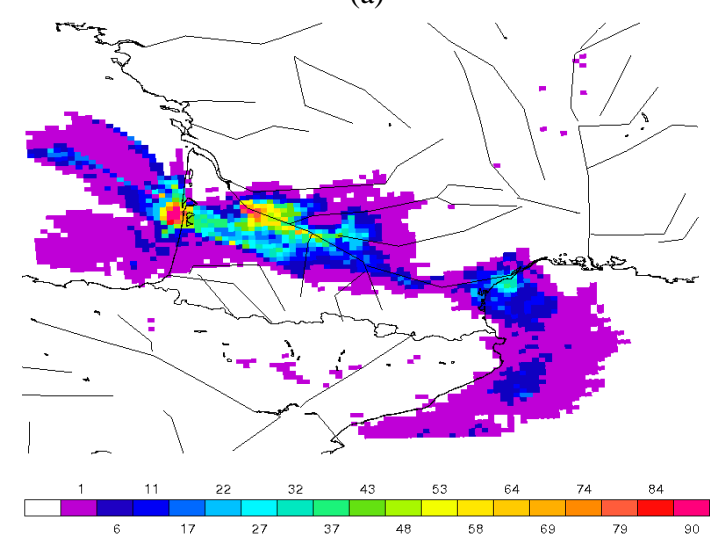

(c)

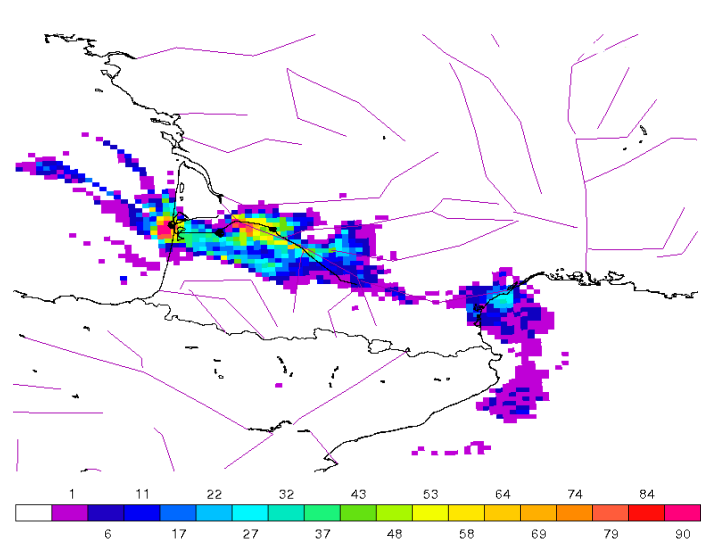

(b)

Fig. 6. Error reduction (\%) on surface fluxes over the 4-day period: (a) Piper Aztec flight (b) 2 towers, (c) 2 towers+10 flights.

for the real Biscarosse tower ( $50 \mathrm{~m}$ above the ground). The most important region of influence covers a large area between Biscarosse and Marmande towers, and also 2 narrow bands due to sea breezes on different days of the experiment. We also see a smaller area at the East of the Pyrenees as with the previous cases. Using the virtual tall Biscarosse tower, the spatial extent of surface influence is reduced overall (Fig. 8b), especially around the tower, and elsewhere is not visibly enhanced. For the boundary concentrations, reduction remains equivalent at less than $1 \%$. The main difference is due to a change in nighttime response. Particles released during nighttime are above the nocturnal boundary layer, compared to the original Biscarosse tower accumulating particles in the reduced mixed layer.

This is a case where our choice to solve for night and day fluxes together has a significant impact. Overall, it seems that the use of tall towers should be treated carefully in inversions on small regions. Although they are easier to model, (hence can use lower data uncertainty) a large part of the observed variability is associated with long range transport, affecting the boundary conditions of the limited domain.

\section{Discussion}

For the second CERES IOP, estimated error reduction larger than $30 \%$ covers an area of about $200 \mathrm{~km}$ in the North-South direction and $100 \mathrm{~km}$ in the eastwest direction. This suggests it is possible to do a meaningful top-down/bottom-up comparison for the pine forest and part of the agricultural area. Aircraft data showed a small but noticeable contribution at the surface, using the same observation error as the one used for daytime tower data. The comparison from Sarrat et al. (2007) showed the relatively smaller observation error for aircraft data modeling compared to near-ground observations, which is mainly due to the lower variability of the $\mathrm{CO} 2$ concentrations at higher altitudes. We have already noted the assumptions about spatial and temporal correlations that underlie these results. Clearly, at the resolution of a few kilometers, more work is necessary on the topic of flux error correlation, both in space and in time.

In our inverse system, boundaries appear to be less well constrained by observations than surface fluxes. The final contribution of boundaries remains limited because particles released in LPDM touch the surface three times on average before leaving the domain after passing once through the 


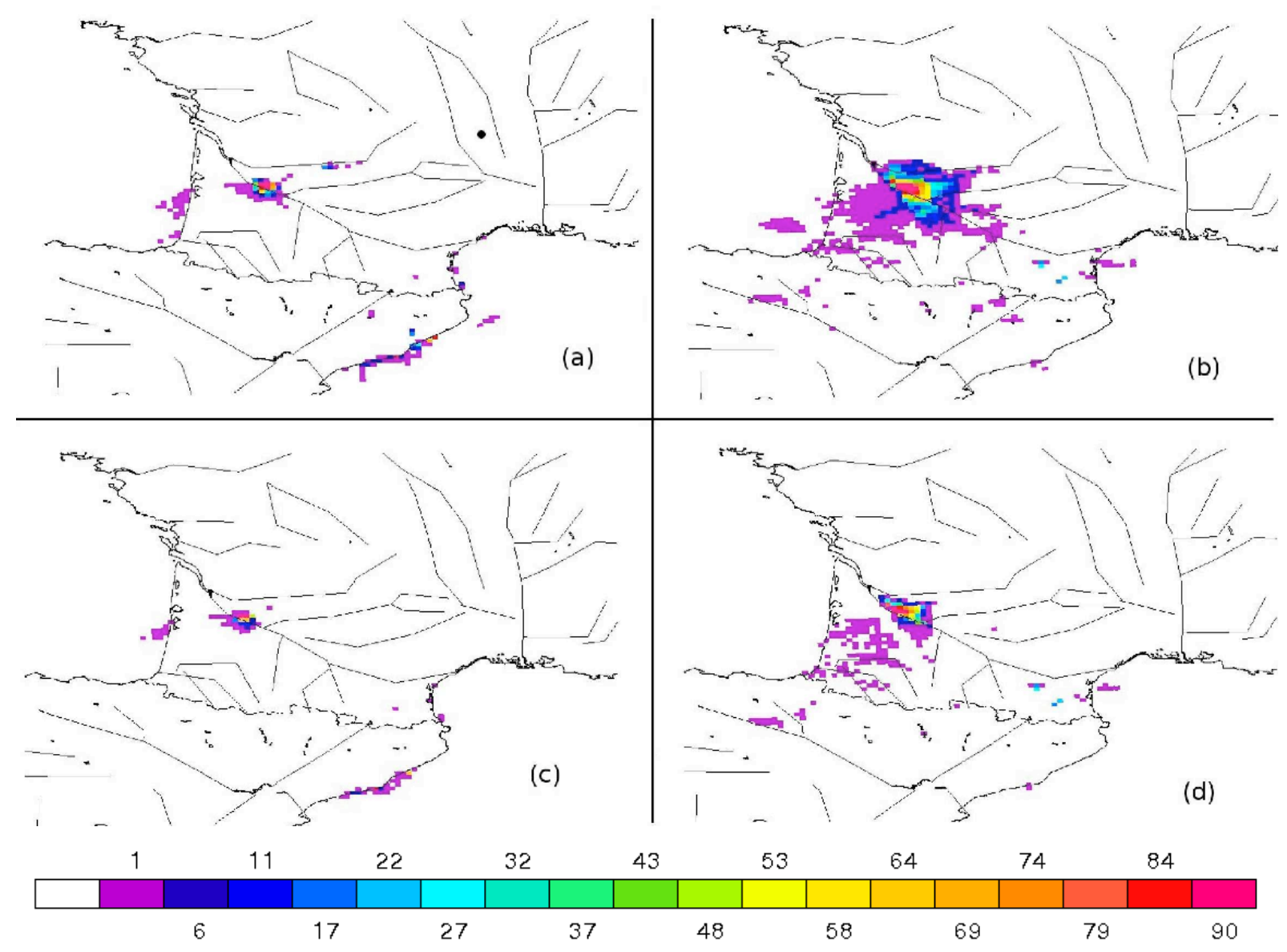

Fig. 7. Error reduction (\%) on surface fluxes over the 4-day period using only the tower measurements: (a) diurnal mean flux, constant observation error of 4 ppm (b) nocturnal mean flux, constant observation error of 4 ppm (c) diurnal mean flux, using only daytime data (d) nocturnal mean flux, using only daytime data.

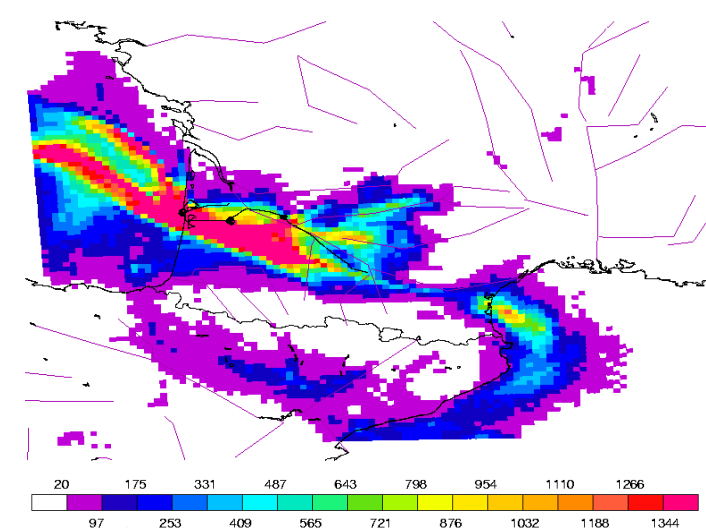

(a)

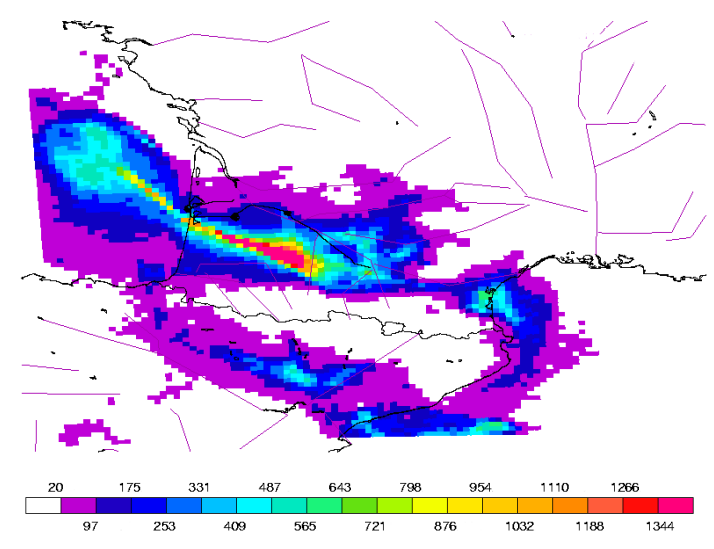

(b)

Fig. 8. Particle distribution over 4-day period: (a) Real Biscarosse tower (50 m), (b) Fictive tall tower at Biscarosse (300 m). 


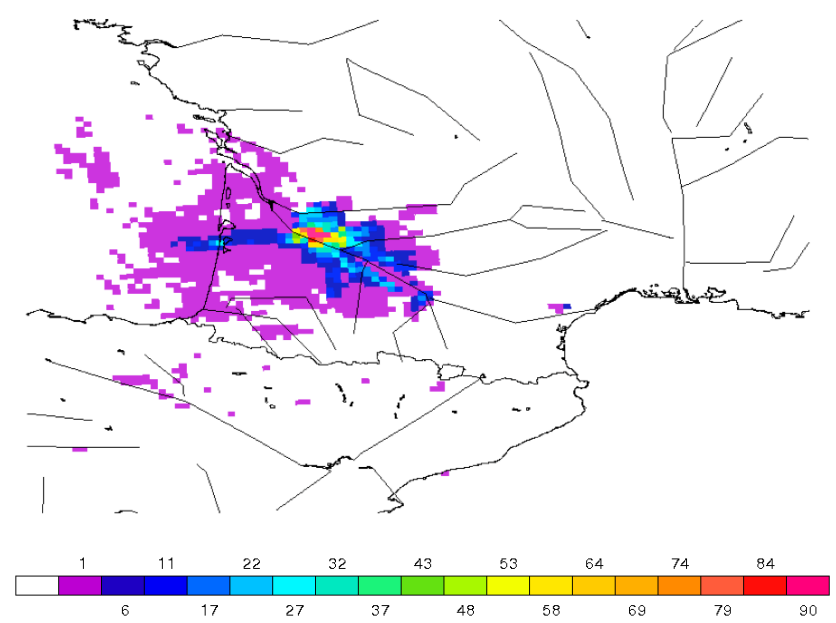

Fig. 9. Error reduction (\%) on surface fluxes over the 4-day period for one mean flux, using only daytime tower observations.

boundaries. For aircraft measurements, the contribution of the boundaries is more important due to the fact that most of the particles released at higher altitudes reach the boundaries without touching the surface. However, even with the use of aircraft, the optimization of the boundary fluxes remains limited because aircraft measurements represent many fewer particles than continuous ground sites. This means also that the impact of the boundaries on final $\mathrm{CO}_{2}$ concentrations observed is reduced. The prior uncertainty of the boundaries was increased to assess its impact on the posterior error. The error reduction for surface fluxes remains constant while high values at the boundaries show higher reductions. The result is explained by Eq. (3). For a given $\mathbf{C}(\boldsymbol{d})$ and $\mathbf{J}$ there is a larger reduction of error if $\mathbf{C}\left(\boldsymbol{s}_{0}\right)^{-1}$ is small, i.e. a large prior uncertainty. The lack of impact on the reduction of error for the surface is explained by the weak coupling between the surface and boundary parts of the inversion.

Overall, for short term mesoscale inversions, the need for constraint at the boundaries is clear for observations in the free troposphere, but not in the boundary layer. Global models seem able to give this information at least in the context of weak mean wind and strong convection near the surface. The use of global models to constrain boundaries might also be critical when using tall towers. As shown by the third experiment, such towers are mainly influenced by large scale motions.

The high spatial resolution used for this inversion shows that the most observable flux contribution comes from regions close to the measuring instruments within the boundary layer. This spatial distribution is strongly dependent on the quality of atmospheric transport, but mesoscale models like MesoNH have shown their ability to reproduce complex dynamical processes in the lower atmosphere during the day
(Sarrat et al., 2007). The nocturnal accumulation of $\mathrm{CO}_{2}$ in the boundary layer at Marmande tower remains lower than observed in the direct simulation (Fig. 2b). The offline coupling with the lagrangian model reinforces this additional vertical diffusion. The integration of the particles near the surface is optimal between $50 \mathrm{~m}$ to $100 \mathrm{~m}$ high during the night, higher than expected. The reduced height of the nocturnal boundary layer explains the diurnal variability. The absolute error on the boundary layer height during the night induces a larger relative error compared to daytime, which is directly related to the modelled $\mathrm{CO}_{2}$ concentration. The error reduction of the diurnal $\mathrm{CO}_{2}$ fluxes is less affected by the larger nocturnal observation error than nocturnal $\mathrm{CO}_{2}$ fluxes. But the final error reduction is larger for the nocturnal component of the fluxes. Considering the inversion setup for one mean flux, the error reduction using the two towers of the campaign is reduced but still covers a few tenths of $\mathrm{km}$ (Fig. 9). We suppose in this experiment the model is able to reproduce the diurnal variability of the $\mathrm{CO}_{2}$ fluxes, as shown in the study of Ahmadov et al. (2007) during the same campaign using the coupled model WRF-VPRM. The observation error was set to $4 \mathrm{ppmv}$ during the day and $100 \mathrm{ppmv}$ during the night following our comparison (Fig. 2). The increase of the diurnal observation error would mainly decrease the error reduction by few percents but won't affect seriously its spatial distribution. For future inversions, the preliminary analysis of flux model errors, and simulated concentrations, will guide the definition of the final state vector, especially the choice of a daily mean or diurnal and nocturnal components. The prior flux correlations will be guided by analysis of flux tower measurements. The error reduction presented here would be affected by these additional elements depending on the hypothesis introduced in the inverse system.

The behaviour of error reduction is sensitive to vertical velocity in the boundary layer. Averaged vertical velocity estimated in a preliminary simulation appeared to be weaker than observed. A simple first approach to examining the importance of this issue is to estimate the impact of strongly varying day/night turbulence intensities and depth of mixing. This can be approximated with vertical turbulent velocities of a few meters per second and mixing depths of one to two kilometers for a strongly convective diurnal boundary layer such as 27 May. The present LPDM parameterization for boundary layer turbulence corresponds to Gaussian but inhomogeneous conditions (Thomson, 1987; Du, 1997). Using enhanced mixing in a test, we found that error reduction was smaller due to a loss of particles to the free troposphere. A more sophisticated planetary boundary layer scheme should be developed to improve the vertical mixing in LPDM. We also examined the vertical mixing over the ocean, mostly dominated by wind shear, weaker than observed at the Biscarosse tower due to the complex dynamical processes induced by the highly negative energy balance at the surface. This development needs the description of other 
dynamic processes such as entrainment and detrainment at the top of the planetary boundary layer. We will investigate such a scheme in the context of an inversion using actual measurements.

Finally, towers are the most important source of information for the inversion of surface fluxes. At the same time, aircraft measurements allow us to constrain the limits with only a small effect on the final surface fluxes and their posterior uncertainties. The combination of these observations defines a complete framework to assess sources and sinks for mesoscale domains.

\section{Conclusions}

We have developed a demonstration system for regional inverse modelling at the meso scale, and tested it for the CERES intensive campaign (2nd IOP). Using available measurement locations and dates, a large part (more than 50\%) of the domain $(300 \mathrm{~km} \times 300 \mathrm{~km})$ is constrained with an error reduction larger than $30 \%$. No spatial a priori correlation was used to enlarge the impact of the data. Concentration measurements on towers play a major role in reducing uncertainties for surface fluxes, whereas aircraft measurements above the planetary boundary layer influence mostly the boundaries. The intensive period of flights improved the error reduction at the surface by 15 to $20 \%$ compared with the two tower-only case. This implies also a reduced importance of boundary conditions compared to surface influence for near ground observations.

Acknowledgements. We wish to thank all participants in the CERES campaign for making their data freely available on the official website (http://carboregional.mediasfrance.org/campagne/ index). CarboEurope is supported by the European Commission under the 6 Framework Programme. This research was funded in part by the US Department of Commerce, National Oceanic and Atmospheric Administration (NOAA), Office of Global Programs, Global Carbon Cycle program, grant number NA040AR4310124.

Edited by: I. Aben

\section{References}

Ahmadov R., Gerbig, C., Kretschmer, R., Koerner, S., Neininger, B., Dolman, A. J., and Sarrat, C.: Mesoscale covariance of transport and $\mathrm{CO}_{2}$ fluxes: Evidence from observations and simulations using the WRF-VPRM coupled atmosphere-biosphere model, J. Geophys. Res., 112, D22107, doi:10.1029/2007JD008552, 2007

Baker, D. F., Law, R. M., Gurney, K. R., Rayner, P., Peylin, P., Denning, A. S., Bousquet, P., Bruhwiler, L., Chen, Y.-H., Ciais, P., Fung, I. Y., Heimann, M., John, J., Maki, T., Maksyutov, S., Masarie, K., Prather, M., Pak, B., Taguchi, S., and Zhu, Z:: TransCom 3 inversion intercomparison: Impact of transport model errors on the interannual variability of regional
CO2 fluxes, 1988-2003, Global Biogeochem. Cy., 20, GB1002, doi:10.1029/2004GB002439, 2006.

Baldocchi, D. D., Falge, E., Gu, L., Olson, R., Hollinger, D., Running, S., Anthoni, P., Bernhofer, C., Davis, K., Fuentes, J., Goldstein, A., Katul, G., Law, B., Lee, X., Malhi, Y., Meyers, T., Munger, J. W., Oechel, W., Pilegaard, K., Schmid, H. P., Valentini, R., Verma, S., Vesala, T., Wilson, K., and Wofsy, S.: FLUXNET: A new tool to study the temporal and spatial variability of ecosystem-scale carbon dioxide, water vapor, and energy flux densities, Bull. Am. Meteorol. Soc., 82, 2415-2435, 2001.

Bousquet, P., Peylin, P., Ciais, P., Quéré, C. L., Friedlingstein, P., and Tans, P. P.: Regional changes in carbon dioxide fluxes of land and oceans since 1980, Science, 290, 1342-1346, 2000.

Carouge, C.: Vers une estimation des flux de $\mathrm{CO}_{2}$ Européen, $\mathrm{PhD}$ thesis, 2006.

Chevallier, F., Viovy, N., Reichstein, M., and Ciais, P.: On the assignment of prior errors in Bayesian inversions of $\mathrm{CO}_{2}$ surface fluxes, Geophys. Res. Letters, 33, L13802, doi:10.1029/2006GL026496, 2006.

Davis, K., Bakwin, P., Berger, B., Yi, C., Zhao, C., Teclaw, R., and Isebrands, J.: The annual cycle of $\mathrm{CO}_{2}$ and $\mathrm{H} 2 \mathrm{O}$ exchange over a northern mixed forest as observed from a very tall tower, Glob. Change Biol., 9, 1278-1293, 2003.

Dolman, A. J., Noilhan, J., Durand, P., Sarrat, C., Brut, A., Piguet, B., Butet, A., Jarosz, N., Brunet, Y., Loustau, D., Lamaud, E., Tolk, L., Miglietta, R. R. F., Gioli, B., Magliulo, V., Esposito, M., Gerbig, C., Krner, S., Galdemard, P., Ramonet, M., Ciais, P., Neininger, B., Hutjes, R. W. A., Macatangay, J. A. E. R., Schrems, O., Pérez-Landa, G., Sanz, M. J., Scholz, Y., Facon, G., Ceschia, E., and Beziat, P.: CERES, the CarboEurope Regional Experiment Strategy in Les Landes, South West France, May-June 2005, Bull. Am. Meteorol. Soc., 87(10), 1367-1379, doi:10.1175/BAMS-87-10-1367, 2006.

Dolman, H., DeMartino, B., Gioli, B., Hutjes, R. W. A., Lindroth, A., Miglietta, F., Millan, M. M., Sanz, M. J., and Schumacher, M.: Regional assessment and monitoring of the carbon balance within Europe (RECAB): Experimental strategy and mesoscale modeling preliminary results, European Geophysical Union, Nice, EGS02-A-06856, 2002.

$\mathrm{Du}, \mathrm{S}$.: Universality of the lagrangian velocity structure function constant (C0) across different kinds of turbulence, Bound. Lay. Met., 83, 207-219, 1997.

Enting, I. G.: Inverse Problems in Atmospheric Constituent Transport, Cambridge University Press, 2002.

Enting, I. G., Trudinger, C. M., and Francey, R. J.: A synthesis inversion of the concentration and $\delta^{13} \mathrm{C}$ of atmospheric $\mathrm{CO}_{2}$, Tellus, 47B, 35-52, 1995.

Filippi, D., Ramonet, M., Ciais, P., Picard, D., Roulley, J.-C. L., Schmidt, M., and Nedelec, P.: Greenhouse airborne measurements over Europe, Geophys. Res. Abstracts, 5, 2003.

Geels, C., Gloor, M., Ciais, P., Bousquet, P., Peylin, P., Vermeulen, A. T., Dargaville, R., Aalto, T., Brandt, J., Christensen, J., Frohn, L. M., Haszpra, L., Karstens, U., Rödenbeck, C., Ramonet, M., Carboni, G., and Santaguida, R.: Comparing atmospheric transport models for future regional inversions over Europe. Part 1: Mapping the $\mathrm{CO}_{2}$ atmospheric signals, Atmos. Chem. Phys., 7, 3461-3479, 2007, http://www.atmos-chem-phys.net/7/3461/2007/. 
Gerbig, C., Lin, J. C., Wofsy, S. C., Daube, B. C., Andrews, A. E., Stephens, B. B., Bakwin, P. S., and Grainger, C. A.: Toward constraining regional-scale fluxes of $\mathrm{CO}_{2}$ with atmospheric observations over a continent: 1 . Observed spatial variability from airborne platforms, J. Geophys. Res., 108(D24), 4756, doi:10.1029/2002JD003018, 2003.

Gerbig, C., Lin, J. C., Wofsy, S. C., Daube, B. C., Andrews, A. E., Stephens, B. B., Bakwin, P. S., and Grainger, C. A.: Toward constraining regional-scale fluxes of $\mathrm{CO}_{2}$ with atmospheric observations over a continent: 2 . Analysis of COBRA data using a receptor-oriented framework, J. Geophys. Res., 108(D24), 4756, doi:10.1029/2003JD003770, 2003.

Gloor, M., Fan, S. M., Pacala, S., and Sarmiento, J.: Optimal sampling of the atmosphere for purpose of inverse modeling: A model study, Global Biogeochem. Cy., 14, 407-428, 2000.

Gloor, M., Bakwin, P., Hurst, D., Lock, L., Draxler, R., and Tans, P.: What is the concentration footprint of a tall tower?, J. Geophys. Res., 106, 17 831-17 840, 2001.

Gurney, K. R., Law, R. M., Denning, A. S., Rayner, P. J., Baker, D., Bousquet, P., Bruhwiler, L., Chen, Y.-H., Ciais, P., Fan, S., Fung, I. Y., Gloor, M., Heimann, M., Higuchi, K., John, J., Maki, T., Maksyutov, S., Masarie, K., Peylin, P., Prather, M., Pak, B. C., Randerson, J., Sarmiento, J., Taguchi, S., Takahashi, T., and Yuen, C.-W.: Towards robust regional estimates of $\mathrm{CO}_{2}$ sources and sinks using atmospheric transport models, Nature, 415, 626-630, 2002.

Keeling, C., D., Piper, S., C., Heimann, M.: A Three-dimensional Model of Atmospheric $\mathrm{CO}_{2}$ transport based on observed winds: 4. Mean annual gradients and interannual variations, AGU, Aspects of Climate Variability in the Pacific and the Western Americas, Geophysical Monograph 55, 305-363, 1989.

Krinner, G., Viovy, N., de Noblet-Ducoudré, N., Ogee, J., Polcher, J., Friedlingstein, P., Ciais, P., Sitch, S., and Prentice, I. C.: A dynamic global vegetation model for studies of the coupled atmosphere-biosphere system, Global Biogeochem. Cy., 19, GB1015, doi:10.1029/2003GB002199, 2005.

Lafore, J., Stein, J., Bougeault, P., Ducrocq, V., Duron, J., Fischer, C., Hereil, P., Mascart, P., Masson, V., Pinty, J. P., Redelsperger, J., Richard, E., and de Arellano, J. V.: The Meso-NH atmospheric simulation system. Part I: adiabatic formulation and control simulations, Ann. Geophys., 16, 90-109, 1998, http://www.ann-geophys.net/16/90/1998/.

Law, R. M., Rayner, P. J., Steele, L. P., and Enting, I. G.: Data and modelling requirements for $\mathrm{CO}_{2}$ inversions using high frequency data, Tellus, 55B, 512-521, doi:10.1034/j.16000560.2003.0029.x, 2003.

Michalak, A. M., Hirsch, A., Bruhwiler, L., Gurney, K. R., Peters, W., and Tans, P. P.: Maximum likelihood estimation of covariance parameters for Bayesian atmospheric trace gas surface flux inversions, J. Geophys. Res., 110(D24), D24107, doi:10.1029/2005JD005970, 2005.

Pérez-Landa, G., Ciais, P., Gangoiti, G., Palau, J. L., Carrara, A., Gioli, B., Miglietta, F., Schumacher, M., Millan, M. M., and Sanz, M. J.: Mesoscale circulations over complex terrain in the Valencia coastal region, Spain, Part 2: linking $\mathrm{CO}_{2}$ surface fluxes with observed concentrations, Atmos. Chem. Phys., 7, 18511868, 2007,

http://www.atmos-chem-phys.net/7/1851/2007/.
Peylin, P., Rayner, P. J., Bousquet, P., Carouge, C., Hourdin, F., Ciais, P., Heinrich, P., and AeroCarb Contributors: Daily $\mathrm{CO}_{2}$ flux estimate over Europe from continuous atmospheric measurements: Part 1 inverse methodology, Atmos. Chem. Phys., 5, 3173-3186, 2005,

http://www.atmos-chem-phys.net/5/3173/2005/.

Peters, W., Miller, J., B., Whitaker, J., Denning, A., S., Hirsch, A., Krol, M., C., Zupanski, D., Bruhwiler, L., Tans, P., P.: An ensemble data assimilation system to estimate $\mathrm{CO}_{2}$ surface fluxes from atmospheric trace gas observations, J. Geophys. Res., 110, 24304, doi:10.1029/2005JD006157, 2005.

Raupach, M. R., Marland, G., Ciais, P., Le Quere, C., Canadell, J. G., Klepper, G., and Field, C. B.: Global and regional drivers of accelerating $\mathrm{CO}_{2}$ emissions, PNAS, 104, $10288-10293$, http: //www.pnas.org/cgi/content/abstract/104/24/10288, 2007.

Rayner, P. J. and O'Brien, D. M.: The utility of remotely sensed $\mathrm{CO}_{2}$ concentration data in surface source inversions, Geophys. Res. Let., 28, 175-178, 2001.

Rayner, P. J., Scholze, M., Knorr, W., Kaminski, T., Giering, R., and Widmann, H.: Two decades of terrestrial Carbon fluxes from a Carbon Cycle Data Assimilation System (CCDAS), Glob. Biogeochem. Cy., 19, 2026, 2005.

Rödenbeck, C., Houweling, S., Gloor, M., and Heimann, M.: Timedependent atmospheric $\mathrm{CO}_{2}$ inversions based on interannually varying tracer transport, Tellus B, 55, 488-497, 2003.

Rodgers, C. D.: Inverse methods for atmospheric sounding: Theory and practice, World Scientific Publishing Co. Pte. Ltd. 2000.

Sarrat, C., Noilhan, J., Lacarrère, P., Donier, S., Dolman, H., Gerbig, C., Ciais, P., and Butet, A.: Atmospheric $\mathrm{CO}_{2}$ modeling at the regional scale: Application to the CarboEurope Regional Experiment, J. Geophys. Res., 112, D12105, doi:10.1029/2006JD008107, 2007.

Sarrat, C., Noilhan, J., Dolman, H., Gerbig, C., Ahmadov, R., Tolk, L. F., Meesters, A. G. C. A., Hutjes, R. W. A., Ter Maat, H. W., Pérez-Landa, G., and Donier, S.: Atmospheric $\mathrm{CO}_{2}$ modeling at the regional scale: an intercomparison of 5 meso-scale atmospheric models, Biogeosciences Discuss., 4, 1923-1952, 2007 , http://www.biogeosciences-discuss.net/4/1923/2007/.

Seibert, P. and Frank, A.: Source-receptor matrix calculation with a Lagrangian particle dispersion model in backward mode, Atmos. Chem. Phys., 4, 51-63, 2004

Stephens, B. B., Wofsy, S. C., Keeling, R. F., Tans, P., and Potosnak, M. J.: The $\mathrm{CO}_{2}$ Budget and Rectification Airborne Study: Strategies for measuring rectifiers and regional fluxes, Inverse Methods in Global Biogeochemical Cycles, Geophysical Monograph 114, AGU, 2000.

Tans, P., Fung, I. Y., and Takahashi, T.: Observational constraints on the global atmospheric $\mathrm{CO}_{2}$ budget, Science, 247, 1431-1438, 1990.

Tarantola, A.: Inverse Problem Theory: Methods for Data Fitting and Parameter Estimation, Elsevier, Amsterdam, 1987.

Thomson, D. J.: Criteria for the selection of stochastic models of particle trajectories in turbulent flow, J. Fluid Mech., 180, 529556, 1987.

Uliasz, M.: Lagrangian particle modeling in mesoscale applications, Environmental Modelling II, ed. P. Zanetti, Computational Mechanics Publications, 71-102, 1994.

Uliasz, M., Denning, A. S., Schuh, A., Richardson, S. J., Miles, N., Davis, K. J., and Zupanski, D.: Estimation of regional $\mathrm{CO}_{2}$ 
fluxes using concentration measurements from the ring of towers in northern Wisconsin, American Geophysical Union, Fall Meeting, 2005.

Vermeulen, A. T., Eisma, R., Hensen, A., and Slanina, J.: Transport model calculations of NW-European methane emissions, Env. Sci. and Policy, 2, 315-324, 1999.

Wang, Y., P., Leuning, R., Cleugh, H., Coppin, A.: Parameter estimation in surface exchange models using non-linear inversion: How many parameters can we estimate and which measurements are most useful?, Glob. Change Biol., 7, 495-510, 2001.
Zupanski, D., Denning, A. S., Uliasz, M., Zupanski, M., Schuh, A. E., Rayner, P. J., Peters, W., and Corbin, K.: Carbon flux bias estimation employing Maximum Likelihood Ensemble Filter (MLEF), J. Geophys. Res., 112, D17107, doi:10.1029/2006JD008371, 2007. 